\title{
SUJEITOS EM CONSTRUÇÃO: A LEITURA E A ESCRITA DE SI
}

\section{ELIANA YUNES}

Pontifícia Universidade Católica do Rio de Janeiro

RESUMO O artigo trata de construção do eu em (auto)biografias de presos comuns, a partir de oficinas de leitura, realizadas com a mediação de leitores experientes, que se desdobram em (auto)escritas de si ou relatos de vida em depoimentos e entrevistas (biografias). o processo de ressubjetivação pela palavra ficcional alcança a construção de uma identidade potencial desconhecida no avesso da vida de exclusão que experimentam. No encontro com as personagens da literatura desenha-se uma compreensão crítica do mundo em que se veem inseridos e uma compreensão distinta das possiblidades alternativas de reinserção social. A experiência realizada em diversas prisões durante a etapa inicial do Proler, disseminou-se em outras iniciativas pelo país, e diverge em quase tudo da proposta oficial do Judiciário, que confunde leitura para a vida com leitura para a remissão de pena.

Palavras-chave: Leitura ficcional. Reconstrução de identidade. Reinserção social

\section{ABSTRACT SUBJECTS IN CONSTRUCTION: READING AND SELF- WRITING}

The article discusses the construction of the self in (auto) biographies of common prisoners, from reading and workshops with experienced readers mediation, which unfold to self-written or reports of life in depositions and interviews (biographies). The process of re-subjectivity by the fictional word reaches the construction of an unknown and potential identity on the reverse of life when they experienced exclusion. At the meeting with the characters of literature, it draws a critical understanding of the world where they are inserted and a distinct understanding of the possibilities of social reinsertion alternatives. The experience held in several prisons during the early stage of Proler ( $\mathrm{Na}$ tional Reading Program) spread in other initiatives across the country, differing in almost all of the official proposal of the judiciary, which confuses reading to life with reading for remission of penalty.

Keywords: Fictional reading. Reconstruction of identity. Social reintegration. 


\section{RESUMEN SUJETOS EN CONSTRUCCIÓN: LA LECTURA Y LA ESCRITURA DE SÍ}

El artículo trata de la construcción del yo en (auto)biografias de presos comunes, a partir de talleres de lectura realizadas con la mediación de lectores expertos, que se despliegan en (auto)escrituras de sí o en relatos de vida en declaraciones y entrevistas (biografias). El proceso de re-subjetivación por la palabra ficcional alcanza a la construcción de una identidad potencial desconocida en el reverso de la vida cuando experimentaran la exclusión. En el encuentro con los personajes de la literatura se dibuja una comprensión crítica del mundo en el que se ven insertos y una comprensión distinta de las posibilidades alternativas de re-inserción social. La experiencia desarrollada en diversas prisiones durante la etapa inicial del Proler (Programa Nacional de Lectura) se diseminó en otras iniciativas en el país, y difieren en casi la totalidad de la propuesta oficial del poder judicial, que confunde la lectura para la vida con la lectura para el tratamiento de la pena.

Palabras clave: Lectura ficcional. Reconstrucción de la identidad. Re-inserción social.

Vou criar o que me aconteceu. Só porque viver não é relatável. Viver não é vivível. Terei de criar sobre a vida. E sem mentir. Criar sim, mentir não. Criar não é imaginação, é correr o grande risco de se ter a realidade. Clarice Lispector (1998, p. 21)

A criação do Proler (1992-1996) - Programa Nacional de incentivo à Leitura, primeira iniciativa para uma discussão efetiva de institucionalização de uma política nacional de leitura, foi baseada em pesquisa, financiada pela Finep, entre 1988/1989. Feita uma revisão das teorias da leitura da hermenêutica à produção de sentidos, passando pelas memórias de escritores, obviamente leitores, durante cinco, anos em cerca de 600 municipalidades brasileiras, implementou-se uma ação conjunta e articulada entre a sociedade civil e o Estado para a formação de um país de leitores, como sonhara Lobato, nos anos de 1920 e Mario de Andrade nos anos de 1930. Mas acabou abortado por picuinhas correntes, tanto em política, quanto em nossos ambientes acadêmicos.

0 intento era promover-se uma estratégia de longa duração para a formação de leitores, nos espaços sociais como um todo, para que a escola e a biblioteca não ficassem isoladas nesta tarefa inglória, mas indispensável, de apresentar a prática da leitura como condição de cidadania e não apanágio de intelectuais. Na proposta inicial, havia uma hipótese teórico-metodológica, publicada ao fim da experiência de cinco anos, na obra pessoal e coletiva Pensar a Leitura ( 2002), que estava aberta a correções de rumo, contribuições de diferentes pesquisadores integrantes do projeto, e observação atenta dos processos em curso, nos diferentes espaços, ambiências e públicos, com que interagíamos, enquanto os procedimentos de ordem estratégica eram implementados. Embora o programa tivesse uma concepção muito ampla do que fosse leitura, 
aplicável a textualidades e diferentes linguagens, decidiu-se começar pelo recurso à literatura, apesar de que pudesse parecer um risco, frente a uma sociedade que já tinha feito um forte retorno à imagem.

O primeiro obstáculo a ser vencido era o estranhamento da linguagem da literatura, superável somente pelo exercício da escuta, da leitura em voz alta, com o ritmo e a cadência devidos, resgatando o que se perdeu da passagem da oralidade à escrita: eis o trabalho da pontuação, para resgatar pausas, ênfases, gestos (YUNES, 2006). A retomada da oralidade, longe de atraso, revelou-se uma experiência encantatória, condição próxima a de contar/ouvir histórias, apesar do vocabulário e da construção sintática sofisticados para o padrão comum da linguagem ordinária, porém extraordinária para a criação de imagens surpreendentes, inusitadas, muitas vezes perdidas no esforço de decifrar os signos. Não carecia serem narrativas mágicas; podia-se ler tanto Marina Colasanti como Rachel de Queiroz, Rubem Braga como Luís Fernando Veríssimo.

Passando à admiração e ao desejo dos ouvintes, a linguagem literária abria-se a outros desafios. Aspiração ao entendimento, busca de sentido, iniciação ao simbólico, construção do imaginário, percepção do contexto e anseio por dizer alguma coisa, mesmo no temor de "falar bobagens". o passo seguinte foi perguntar-se "o que faço com isto", ou seja, o velho temor da (in) compreensão textual: o que o texto me pergunta e o que devo responder? Ao contrário, não lhes ocorria procurar: o que eu tenho a perguntar ao texto e o que o texto pode me responder?

A questão então, que aí se coloca é: por que não sei fazer perguntas ao texto? Descobre-se, de forma perturbadora, que não sabendo quem somos, que experiências tivemos, que acervos de vida portamos ou qual nosso repertório de histórias, dificilmente haverá diálogo com o texto. Para a troca com o que ele me traz, supõe-se o que eu tenho para trocar com ele, pois a interpretação não está no texto, como um enigma, mas na interação que estabeleço com ele, seu contexto original ou atual, minhas circunstâncias de ontem e de hoje.

Desta descoberta surge a demanda pela reconstituição da memória de si, que nunca é a memória de fato em si, do acontecido, mas do sentido experienciado pela razão e pelos afetos, cujas sensações e imagens recobram vida com outra cara, outro figurino, na rememoração; e nunca é a memória solitária do eu, mas do nós, das relações e seus ecos, como no texto muitas vezes acontece e faz acordar outras vozes. Polifonias que ameaçam a objetividade e as certezas em que nos seguramos.

Como a linguagem adquirida, com sua gramática invisível, não nos diz muito sobre as sequências pobres e automatizadas que empregamos, perdemos de vista a força criadora da palavra, com recônditas ressonâncias e poder de dar forma ao mundo, em princípio, ao mundo de cada um. Logo, ao mundo grande. Lembro que o tamanho do mundo tem a dimensão de nossa linguagem. (WITTGENSTEIN, 1999). Assim, quando se começa a ter memória e expressões capazes de dar materialidade sonora e semântica às palavras e textos, passamos a reconhecer-nos neles e a atribuir-lhes alguma significância, que dorme nas entrelinhas, e outras que cabem nos vazios do dizer, sem que se alcance a completude no dito. Entre a realidade que desenhamos e o real inacessivel - a verdade que obcecadamente queremos -, um abismo e a intolerância com o enigma, a insuportável borda do mistério. A língua os explora, as línguas, sobretudo a das artes, no seu limite, nas fronteiras do silêncio: daí a poesia, a mística, a metáfora.

Começa daí a jornada sem fim do leitor, em busca desta inteireza que lhe confortaria o ânimo, de entender a si e ao mundo. Fora isto, o que resta é a brutalidade dos gestos, das armas, da violência. 
Freud (1972) aponta que a falta da linguagem verbal na criança é compensada pelo choro, pelos gritos e pontapés. Mas também reconhece que a linguagem sem fôlego do poeta só encontra paralelo na linguagem desajustada da criança, que escapa à prisão da língua. Em ambas as situações, essas linguagens correspondem à demanda de uma experiência cujos canais de comunicação perscrutam saídas nada triviais. Se não entendemos o jogo da linguagem, o sistema em que o mundo, a realidade está forjada - ou, de outro modo, as ideologias que envolvem os indivíduos - o sentimento de exclusão pode gerar muita reação e violência. Ou entendê-lo sem ter argumentos humanos, isto é, discursivos, a muita incompreensão e impotência podem escoar de volta à barbárie.

Por isto a educação tem seu papel relevante, menos por nos ajustar ao mal-estar na cultura, mais por alargar os horizontes potenciais desta mesa cultura, desde que feita com ética, ou seja, em consideração à existência do outro. Assim, compreensão e aprendizado participam do movimento que aproxima o já sabido, do novo e desconhecido. Há, portanto, que se partir do que os homens sabem, para caminhar com eles ao que não sabem, ainda (ARENDT, 1979). A teoria do mundo na mente combina o conhecimento prévio com a memória de longo prazo, que precisa ser atualizada a cada nova interpelação, seja pelo imaginário que a expande, seja pela concepção que a surpreende.

Esta operação é complexa, dispõe de muitas dobras. A leitura é maior que o código escrito e a decifração de seus caracteres. A palavra, em seu contexto, ressoa sujeita a variáveis diversas, psicológicas, linguísticas, sociais, que atravessam o espaço entre o autor e seu mundo de significação para se apresentar ao leitor. Este precisa mobilizar seu repertório de vida e seu próprio contexto para dialogar e expandir os sentidos possíveis. É nesta prática que pouco a pouco se desenvolve o conhecimento, visto agora não apenas como a apropriação da informação, mas como construção do si-mesmo, seu corpo, sua história, suas escolhas, viabilizando a transformação do lido e do lente, em leitor e eleitor das significâncias plausiveis, segundo a ordem da leitura. Esta concepção estabelece com alguma propriedade o processo de desenvolvimento da (inter)subjetividade (uma construção que nasce do experienciado e se projeta na relação com outros), capaz de espernear contra a subjetivação, (submissão a sistemas de massificação) (GUATTARI; ROLNIK, 1996) e a admissão das comunidades interpretativas em que este sujeito se insere, na proximidade fisica e na distância pelas novas tecnologias de comunicação, a condição intersubjetiva que institui, ainda que na busca de uma singularidade, uma assinatura pessoal.

É neste sentido que a leitura crítica - de discernimento das coisas e das palavras, dos sentidos e seus efeitos - pode se constituir em instrumento de realocação do sujeito no mundo. Ao se deparar nesta situação, o impulso irresistivel é o de contar, de elaborar outro texto que dê conta da "realidade" agora vivida por ele. Passa de ouvinte a falante, com voz própria e palavra que o represente. De leitor de outros, passa a autor de si. Em anexo, estão os livros que os presos elegeram como seus, nestes últimos anos.

$$
* * *
$$

O Proler atuou em muitos espaços, das escolas e bibliotecas aos shoppings e meios de transporte, das comunidades excluídas aos hospitais e asilos. Um dos mais impactantes trabalhos de formação dos leitores - ao qual quero me reportar aqui - está no relato dos mediadores que foram vivê-lo em prisões, entre criminosos recusados no convívio social. Ali, onde a educação é rarefeita, o descaso rotineiro, a brutalidade, a única linguagem, ins- 
talar a prática leitora, como saneamento da dessubjetivação (DELEUZE, 2000) e recomposição da gênese da subjetividade, parecia quase impossivel, para além dos riscos que implicam os jogos de poder atrás das grades. No entanto, atrás da oferta de narrativas ficcionais, muitas realistas, e de poesias, desvelaram-se possibilidades inestimáveis na percepção do eu e dos outros. Em Vitória da Conquista, em São Paulo, em Porto Alegre, para citar apenas três ocorrências duradouras, publicaram-se relatos e depois as obras de detentos que imprimiram novo rumo a suas vidas a partir da leitura. Aqui chego ao tema deste congresso: (auto)biografias.

Mesmo os de mera alfabetização, encontraram em disponiveis escrevinhadores à la Central do Brasil, o suporte para relatar suas histórias de vida, suas (auto)biografias de penitentes e resistentes pelas quais, se não alcançaram remissão de pena - hoje, um capítulo bastante discutivel do Judiciário para propor compensação do delito - oferecem um testemunho inequívoco do papel que a leitura pode desempenhar em suas vidas. Dos livros lidos aos livros produzidos, uma revolução na compreensão do mundo e uma disposição de autocrítica, de crítica e de responsabilidade pessoal.

O papel da (auto)biografia aqui, não se propõe a uma avaliação do gênero recentemente admitido no universo das altas letras, mistura de fato e versão, de verdade e ficção, de imaginário e confissão. A leitura das obras (auto) biográficas de diversos presos anônimos demonstra cabalmente como a prática da leitura, numa perspectiva de formação interdisciplinar, longe de fórmulas e conceituações, assim como de explicitações teóricas e didatismos, foram capazes de induzir à construção do simesmo, através de um relato em que o tom confessional prevalece, mas sem pieguices e edulcorações de penitentes. Recordações, afe- tividades, sofrimentos afloram com a capacidade de gestar, um nome novo (mas velho, o nome de batismo, frente às alcunhas que ganham no crime), um sujeito cujo discurso é um desenho de si que ao próprio surpreende na imagem que cresce diante da travessia feita: mas este sou eu?

Do meio da bandidagem anônima, da massa de desajustados sociais, dos excluídos do direito, emergem personagens vívidos, com aspirações insuspeitadas, com reconsideração daqueles "outros", que tentaram ajudar e dos que os afundaram na lama da violência crua. Os textos, nos cadernos em que a caligrafia, tíbia e vacilante, avança, vão ganhando força, à medida em que leem e releem para o grupo e para os mediadores - porque há de se tê-los - suas histórias. Naquele interstício, há como uma introspeção, não para se decifrar - caminante no hay camino, se hace el camino al andar, nos diz o poeta espanhol Antonio Machado - mas para se apresentar, de viva voz, longe das armas, como sujeito de direito. Entre a heterobiografia e a autobiografia, a biografização institui-se como processo de identificação junto à coletividade tanto quanto à construção de uma identidade de si. A mediação narrativa tem, pois, um caráter interpretativo, mas também formativo e educativo. Os relatos de Marcinho VP e de Nem (BARCELOS, 2012; GLENNY, 2016) foram interpostos por entrevistadores e o que ouvimos e lemos é uma composição entre o dito e o não-dito, o entrevisto nos encontros gravados, mas ainda inacessiveis ao público. Talvez, como propõe Benjamin (2013), sejamos como os anjos da história que avançam de costas e só podem ver as ruínas do que já passou.

Por outro lado, as biografias sem preocupações de ordem narrativa, de ajuste acadêmico-literário, vão desembocando da nebulosa de ocorrências e memórias, das conversas com 
outros presos e de encontros improváveis, em histórias pessoais que bordejam uma nova identidade, reconstruída sobre as ruínas da primeira, alienada, como passaporte para uma aceitação social, com suas mazelas admitidas, mas seu desejo de ser outro.

Outro? Quem seria este outro? No ambiente inóspito e insalubre das prisões - em todos os sentidos - como é difícil ver no outro, amargurado e revoltado, desde sempre, a imagem que the permita fazer o percurso do reconhecimento (RICOEUR, 2014). Considerar o outro como alguém sobre quem projeto e com quem comparo minhas próprias penas e misérias, demanda um duplo esforço, já que a distância não permite reconhecê-lo, para reconhecerme novo, e o contraponto raras vezes escapa do especular. Aí não haveria o salto para a ressubjetivação (AGAMBEN, 2002), que permitisse falar de um egresso com espaço e acolhimento na vida social. Cabe reinventar-se, de modo convincente, para o outro, mas para si, antes de nada. O espelho efetivo está no papel, o seu, finalmente, re-trato. Ali, paradoxalmente mais vivo - como indica Martha Nussbaum, em seu Justiça poética (1997) - no romance, nas novelas, nas crônicas e contos, pelo filtro da ficção melhor se vê o homem e sua ambiguidade inelutável. Não o sujeito apenas, mas a humanidade. A interação com as personagens faz de nós outras personagens de uma história, a que escrevemos no dia a dia, agora entendida como mais "real", surreal, porque escrita para dar-se a conhecer, a reconhecer-se. O poeta pernambucano, o proeminente lírico Bandeira, diz na abertura de sua poesia reunida: "Estrela da vida inteira/ da vida que poderia ter sido e que não foi/ poesia, minha vida verdadeira" (BANDEIRA, 2007).

Entre os anônimos que imergiram para os seus, alguns emergiram para a mídia, sobreviventes. Luiz Mendes descobre a biblioteca no presídio de segurança máxima, pelas mãos de um professor de teoria literária e através da leitura de Proust, Dostoievski, Shakespeare, acaba nas mãos de Antonio Abujamra, para uma entrevista-depoimento, disponivel no youtube. Sua autobiografia, Memórias de um sobrevivente (MENDES, 2001), acaba por darthe uma personalidade, transformá-lo em persona, e permitir uma reentrada, como il faut, na vida social.

Depois de uma condenação de trinta anos, entre assassinatos e assaltos, a (auto)biografia mais se parece a uma alterbiografia, com recursos de relato ficcional. Contudo, as imagens, entrevistas, reportagens e palestras com que ganha, hoje, a vida, garantem que do percurso de leitor da obra romanesca passou a escritor de sua própria vida, "inventando" um nome e uma história que, longe de querer ser exemplar, como nas biografias lapidarmente ficcionais do século XIX, que compõem a descoberta do si, não como idem, mas como ipse, segundo a percepção diversa da identidade: uma que se confere na carteira com foto e na exigência burocrática, o eu no tempo do enunciado; outra que distingue o vivido do relatado, pois sabe que há biografias reconstruídas - o eu no tempo da enunciação - mas não mentirosas e que dão a ver sujeitos antes inexistentes (RICOUER, 2014).

A diferenciação está posta na consideração de uma realidade e de uma verdade que se alteram no tempo, com os movimentos de se ver, ler, reler, ao abrir-se ao outro e narrar-se. Se o sujeito constitui-se na linguagem e em uma práxis social (BAKHTIN, 1994), o resultado de um programa de leitura em casas de reclusão não pode aspirar ao domínio da teoria literária como faz o projeto curitibano de remissão da pena, com provas semelhantes às de vestibular ou de cursinhos. Narrando-se, ocorre um movimento de projetar-se como um outro, descobrindo-se, ao olhar de outrem, com quem participa de uma coletividade. Como al- 
terbiografia ou autoficção, independente dos conceitos operacionais da literatura, a escrita de si, no contato com a literatura e no diálo-

\section{Referências}

AGAMBEN, G. Homo sacer: o poder soberano e a vida nua I. Tradução de Henrique Burigo. Belo Horizonte: Editora UFMG, 2002.

ARENDT, H. Entre o passado e futuro: seis estudos sobre pensamento político. Tradução de Mauro W. Barbosa de Almeida. São Paulo: Perspectiva, 1979.

BAKHTIN, M. The bakhtin reader. London: Pam Morris, 1994.

BANDEIRA, M. Estrela da vida inteira. Rio de Janeiro: Nova Fronteira, 2007.

BARCELOS, C. Abusado: dono do morro D. Marta. Rio de Janeiro: Record, 2012.

Central do Brasil, de Walter Salles, 1998.

BENJAMIN, W. O anjo da História. Tradução de João Barrento. 2. ed. Belo Horizonte: Autêntica, 2013.DELEUZE, G. Mil platôs. Tradução de Aurélio Guerra Neto e Célia Pinto Costa. Rio de Janeiro: Editora 34, 2000.

FREUD, S. Psicopatologia da vida cotidiana. Madrid: Alianza, 1972.

GLENNY, M. 0 dono do morro: um homem e a bataIha pelo Rio. São Paulo: Cia. das Letras, 2016.

GUATTARI, F.; ROLNIK, S. Cartografias do desejo. Pe- go da mediação, funciona como construção de uma subjetividade em processo, que não se esgota no texto publicável.

trópolis, RJ: Vozes, 1996.

LISPECTOR, Clarice. A paixão segundo G.H. Rio de Janeiro: Rocco, 1998.

MENDES, Luiz Alberto. Memórias de um sobrevivente. São Paulo: Cia. das Letras, 2001.

NUSSBAUM, M. C. Cultivating Humanity: a classical defense of reform in liberal education. London: Harvard University Press, 1997.

RICOEUR, P. Percursos do reconhecimento. Tradução de Nicolas Nyimi Campanario. São Paulo: Loyola, 2007.

RICOUER, P. 0 si-mesmo como outro. Tradução de Ivone C. Benedetti. São Paulo: Martins Fontes, 2014.

WITTGENSTEIN, L. Investigações Filosóficas. Tradução de José Carlos Bruni. São Paulo: Nova Cultural, 1999.

YUNES, E. Pensar a palavra: complexidades. Rio de Janeiro: Editora PUCRJ; São Paulo: Loyola, 2002.

YUNES, E. Oralidade, escrita e pensamento. In: AVZARADEL, J. R. Sobre a linguagem e o pensar. Rio de Janeiro: Casa do Psicólogo, 2006. p. 131-146.

Recebido em: 28.07.2016

Aprovado em: 30.10.2016

Anexo:

\section{Os best-sellers das prisões}
1. A menina que roubava livros, Markus Zusak
2. O menino do pijama listrado, John Boyne
3. O caçador de pipas, Khaled Hosseini
4. Nunca desista dos seus sonhos, Augusto Cury
5. Apanhador no campo de centeio, J. D. Salinger
6. O futuro da humanidade, Augusto Cury
7. A cabana, William P. Young
8. O vendedor de sonhos, Augusto Cury
9. Os espiões, Luis Fernando Verissimo
10. O pequeno príncipe, Antoine de Saint-Exupéry

Fonte: Departamento Penitenciário Nacional. Dados divulgados em julho de 2012 referentes às penitenciárias federais. 
Eliana Yunes é doutora em Linguística, pela Universidade de Málaga, e em Literatura pela PUC-Rio (1986). Mestre em Letras pela Pontifícia Universidade Católica do Rio de Janeiro. Pós-Doutorada em Leitura, pela Universidade de Colônia. Atualmente, é professora associada da PUC-Rio, e professora visitante em diversas universidades brasileiras e do exterior. Criou, para a Biblioteca Nacional, o Programa Nacional de Leitura (Proler), é assessora do Cerlalc/Unesco, e assumiu a direção da Cátedra Unesco de Leitura no Brasil, entre 2006 e 2013, quando passou ao Instituto Interdisciplinar de Leitura da PUC-Rio (iiLer), cujo o setor de pesquisas e publicações coordena hoje, assim como preside seu Conselho de Desenvolvimento.e-mail: eliana.yunes@gmail.com.

Cátedra Unesco de Leitura PUC-Rio - R. Marques de São Vicente, 225 - CEP: 22453-900/Gávea-RJ Rio de Janeiro, RJ Brasil 